Phenolphthalein and its halogen products, phenoltetrachlorphthalein and tetrabromphenoltetrachlorphthalein do not differ markedly in their pharmacological behavior. Both phenolphthalein and its tetrachlor derivative are non-irritant when applied to the mucous membrane, to open wounds, and when injected subcutaneously. A subcutaneous injection of $0.40 \mathrm{~g}$. in man causes a laxative action lasting four to six days. This prolonged action along with its low degree of toxicity makes it a hypodermic purgative of much promise. When subcutaneously injected the tetrachlor derivative is absorbed and finally excreted into the bile only. Phenolphthalein administered in the same way escapes in part in the urine, when given per os it may appear in small quantities in both bile and urine, but when the tetrachlor compound is given by mouth none of it appears in the bile or in the urine. The large intestine may absorb these drugs from their solution in bile and become thoroughly saturated with them.

6. "Clavin, Vahlen's Active Constituent of Ergot," by D. Vanslyke. A sample of Vahlen's "clavin" showed upon analysis the following content: leucin, 39.1, iso-leucin, 22.3, and valin 37.1 per cent.

7. "The Effect of Collodion on the Amanitahemolysin." Amanita-hemolysin when dialyzed in collodion sacs loses its hemolytic action completely. Likewise when in contact 24 to 36 hours with granular collodion previously boiled in one per cent. sodium chloride solution and washed with dilute alkalies the hemolysin loses its hemolytic action. Solanin is not affected, but saponin sometimes is.

8. "The Distributions of Poisons in the Amanitas," by W. W. Ford. Nearly twenty species of amanitas were examined and the three most important poisons found in these fungi are muscarine, hemolysins and toxins. By the methods used even one or two plants furnish sufficient analytic material to establish the properties of the fungus suspected of being poisonous.

9. "On the Pharmacological Action of Iodiodoso- and oxyiodosobenzoic Acids," by A. S. Lovenhart and W. E. Grave. Intra- venous injections of $\mathrm{N} / 20$ solutions of sodium iodosobenzoate or oxyiodosobenzoate acids cause an immediate and marked depression of the respiratory center, which seems to be identical with ordinary apnœa caused by excessive ventilation. This and other physiological phenomena seem to indicate that the oxygen bound to the iodine in iodosobenzoic acid is physiologically active.

\section{AN EARLY NOTE ON FLIES AS TRANS- MITTERS OF DISEASE}

IN these days when we are just coming to realize what powerful agents insects are in the dissemination of infectious diseases, it is interesting to read on pages 385 and 386 in Edward Bancroft's "An Essay on the Natural History of Guiana in South America," published in London in 1769, concerning a disease called "Yaws" very prevalent in Guiana:

The Yaws are spungey, fungous, yellowish, circular protuberances, not rising very high, but of different magnitudes, usually between one and three inches in circumference. These infest the whole surface of the body, and are commonly so contiguous that the end of the finger can not be inserted between them; and a small quantity of yellowish pus is usually seen adhering to their surface, which is commonly covered with flies, through the indolence of the Negroes. This is a most troublesome, disagreeable disorder, though it is seldom fatal. Almost all the Negroes, once only in their lives, are infected with it, and sometimes the Whites also, on whom its effects are much more violent. It is usually believed that this disorder is communicated by the flies who have been feasting on a diseased object, to those persons who have sores, or scratches, which are uncovered; and from many observations, I think this is not improbable, as none ever receive this disorder, whose skins are whole; for which reason the Whites are rarely infected; but the backs of the Negroes being often raw by whipping, and suffered to remain naked, they scarce ever escape it.

The "Yaws" according to the Standard Dictionary is: "A contagious tropical skindisease characterized by small, dusky red spots that develop into raspberry-like tubercles, sometimes ulcerating: often of long continuance: frambœsia." 
Bancroft was a physician, who resided on the river Demerara, from which he wrote letters to his brother under dates July 8-November 15,1766 . In 1769 , these letters were collected and published in a volume, under the above title, dedicated to William Pitcairn, M.D., fellow of the Royal College of Physicians in London and Physician of St. Bartholomew's Hospital. The copy from which this extract is taken may be found in the Library of Congress at Washington.

\section{E. W. GUDGER}

State Normal College, Greensboro, N. C.

\section{SPECIAL ARTICLES}

GLACIATION IN THE SAN BERNARDINO RANGE, CALIFORNIA

While engaged in the study of the mountains of southern California the past summer the writers spent a week about the slopes of San Gorgonio Mountain, the highest point of the San Bernardino range. The important discovery was made of unmistakable signs of former glaciation upon its northern slope. This is a fact of considerable interest because it has hitherto been assumed that the southernmost point of glaciation in the United States was in the Sierra Nevadas, nearly two hundred miles to the north.

The San Bernardino range is topographically distinct from any other mountains of southern California. It appears to be much younger than the San Gabriel range, from which it is separated by the Cajon Pass, and also to have had a different history from the San Jacinto Mountains, which lie to the south on the opposite side of the San Gorgonio pass.

The topography of the range is marked by broad elevated valleys, and plateau-like ridges. There are several undrained basins quite similar to those in the desert immediately adjoining on the north, and it seems reasonable to assume that the range as a whole is an uplifted fault block of what was once topographically a portion of the Mohave desert.

The highest portion of the range forms a rather sharp ridge about six miles long and extending a little north of west and south of east. San Bernardino Mountain forms the western end of this ridge with an elevation of 10,630 feet, while the eastern end is known as San Gorgonio Mountain with a height of 11,485 feet. The Santa Ana River, the main stream in the range, drains the northern slope of this ridge, receiving its large permanent flow of cold water from the glacial gravels and the snow banks which linger late in the season in the heads of the protected cañons.

The largest glacier existed on the northwest slope of San Gorgonio in a semicircular basin made by a northerly curve of the ridge running westerly to San Bernardino Mountain. Here is a true glacial cirque, and from its margins well-characterized morainal ridges extend downward for about a mile into the basin of the South Fork of the Santa Ana River, and block a small tributary from the east. Above the dam thus made is a body of water about a quarter of a mile across known as Dry Lake. The lower marginal moraine reached fully three quarters of a mile below the lake, the total width of the glacier at its lower end being indicated by this distance. The rock débris on its lower side forms a great wall across the valley 300 to 400 feet high. The glacier appears to have been overloaded with débris and after having first reached the lowest point where there is a great quantity of partly modified morainal material, to have been crowded progressively eastward back toward the present Dry Lake. In places two to three marginal moraines appear and several basin-like depressions resembling kettle holes. No bedrock is visible in the path of the glacier and scratched boulders were not recognized with certainty. The granitic rocks are coarse and crumble rapidly and it is not to be wondered at that no boulders thus marked were seen. Great springs issue from the lower margin of these glacial gravels, forming a typical mountain meadow with abundance of grass and a cool bracing air.

Another typical cirque basin lies close up under the northeast crest of San Gorgonio, and contains snow drifts nearly all summer. 